deserción de sus colonos y el abandono de sus incipientes asentamientos.

Palabras clave: colonización, litoral aisenino, Estado, fracasos.

\section{Palena, Quitralco y Melimoyu: Intentos fallidos de colonización en el litoral de la Región de Aysén (1889-1983)*}

Palena, Quitralco and Melimoyu: Failed attempts at colonization on the coast of the Aysén region (1889-1983)

Alejandro Marín ${ }^{\star *}$

\section{Resumen}

El siguiente trabajo tiene como objetivo dar a conocer los resultados preliminares de una investigación que busca estudiar las colonizaciones fallidas en los sectores de Bajo Palena o Isla de Los Leones (1889), Quitralco (1950) y el último intento llevado a cabo en las cercanías del volcán Melimoyu (1983). Al ahondar en sus fracasos y desaciertos, es posible encontrar una serie de factores o elementos en común, los cuales provocaron la

* Esta investigación nace a partir del trabajo: "Colonización tardía del litoral norte de Aysén, el nacimiento de Puerto Gala y el Padre Ronchi (1985-1999)", cuyo autor es Alejandro Marín Lleucún.

Sociedad de Historia y Geografía de la Región de Aysén. Correo electrónico: keeptheflames@gmail.com

\begin{abstract}
The objective of the following research is publishing the preliminary results of an investigation which pretends to study the failed colonization to the subsequent areas: Bajo Palena or Isla de Los Leones (1889), Quitralco (1950) and the last attempt carried out in Melimoyu volcano surroundings (1983). When analyzing deeply the failures and mistakes, it is possible to find out a number of factors and elements, which caused the settlers desertion and the abandonment of the incipient settlements.
\end{abstract}

Key words: colonization, Aysén coast, State, failures.

\section{Introducción}

La Región de Aysén es una de las más recientes en nuestro país, sus últimos pueblos Puerto Gala y Puerto Gaviota ${ }^{1}$ se fundaron en el año 1999. El poblamiento interior de este territorio, a finales del siglo XIX y principios del siglo XX, guarda relación con la expansión de las grandes concesiones ganaderas, y la migración de sus primeros colonos espontáneos provenientes de la zona sur de nuestro país y de la vecina República Argentina.

Véase Brinck et al. (2011) 
El contexto de esta época está marcado por los diferendos limítrofes que mantenía Chile con Argentina, por este motivo se inició el reconocimiento de la Patagonia Occidental, mediante una comisión exploradora encomendada al eminente geógrafo Hans Steffens. En compañía del ingeniero Ricardo Mitchell, el naturalista Santiago Hambleton y el mayor del ejército Conde Von der Schulenburg exploraron el territorio situado entre los 46 y 48 grados de latitud, descubriendo un río al que llamaron Baker, y otros dos, los que bautizaron como Bravo y de la Pascua (Carrasco 2002).

El primer viaje que realizó Steffens dio un gran valor comercial a estas tierras desde el punto de vista de la actividad pastoril (Martinic 1977). Esto incidió en los primeros contratos de arrendamientos que se celebraron entre el Estado chileno y distintos consorcios empresariales, los cuales detentaban las zonas de explotación ganadera-maderera, prometiendo el establecimiento de colonos y de las primeras vías de comunicación para los futuros pueblos. La Sociedad Industrial Aysén fue una de las primeras en establecerse en la Patagonia, junto con muchas de estas sociedades ${ }^{2}$ que sirvieron de base para las demás (Pomar 1923), las cuales compitieron por los contratos de arrendamiento y por los lugares que ofrecían las mejores condiciones para sus negocios, incumpliendo gran parte de las promesas de colonización (Osorio 2014).

La migración de los primeros colonos particulares obedeció a las leyes de colonización

A inicios del siglo XX el Estado otorgó 13 permisos de ocupación a diferentes empresarios, muchos de ellos se unieron o cedieron sus derechos. De esta manera, nacieron las tres concesiones más importantes: Sociedad Ganadera Río Cisnes, la Sociedad Explotadora del Baker, y la Sociedad Industrial Aysén. y la repatriación de chilenos desde la Argentina (Ibáñez 1972-1973). La llegada de estos pioneros a la zona de disputa de los grandes consorcios ganaderos no fue bien vista por los estancieros, ya que se radicaron en los terrenos que colindaban con sus dominios. Estos colonos debieron soportar reiterados episodios de violencia al ser tratados como bandidos y ladrones, llegando incluso a muchos intentos de desalojo por la fuerza y de manera ilegal (Ivannof 2002).

El litoral de Aysén no estuvo ajeno a las actividades empresariales de lazona continental. A mediados del siglo XIX, los archipiélagos de los Chonos y Las Guaitecas formaban parte de la gobernación marítima de la provincia de Chiloé, y eran puntos estratégicos de los empresarios madereros chilotes (Morales 2014). En el año 1859 Felipe Westhoff fundó el puerto de Melinka, y fue designado subdelegado marítimo de estos archipiélagos (Vidal 1905). La presencia de este empresario aumentó los movimientos migratorios temporales de trabajadores chilotes, cuyas labores consistieron en extraer grandes cantidades de ciprés para la fabricación de durmientes (Westhoff 1867), además de aprovechar el guano de los lobos marinos (Simpson 2011).

Posteriormente, esta actividad se mantuvo durante la década de 1920 de la mano de Ciriaco Álvarez, "El rey del ciprés", sus negocios estuvieron enfocados en la elaboración de postes y tutores para viñedos en el centro norte del país (Torrejón et al. 2013). El avance chilote continuó más al sur (Islas Huichas), desarrollando actividades paralelas a las forestales, consistentes en la caza de lobos marinos (cuero y aceite), gatos de mar (peletería), y deshidratación de pescados y moluscos (Saavedra 2005). En la década de 1930 comenzó 
un lento proceso de sedentarización de los nómades del mar, específicamente en Puerto Aguirre y Caleta Andrade, en búsqueda de moluscos (choro zapato), lo que coincide con el nacimiento de las primeras plantas conserveras en la década de 1940: Copa, Ancla, Phoenix (Ortega y Bruning 2004).

El primer origen de la colonización costera está basado en la expansión chilota madererabentónica (Saavedra 2011), y un proceso de sedentarización de sus trabajadores en los canales de la Patagonia. Esto se refiere a la explotación del ciprés y el nacimiento de Melinka (1859) en los archipiélagos de las Guaitecas y Los Chonos, además de una diversificación productiva, orientada a la extracción de recursos bentónicos en Puerto Aguirre (1940) o Islas Huichas. El segundo origen se inserta dentro de las políticas de colonización dirigidas por el Estado, quien se encargó de formalizar los asentamientos humanos derivados de los poblamientos espontáneos (nacionales y extranjeros) y las concesiones ganaderas: Puerto Aysén (1928), Puerto Cisnes (1954) y Puyuhuapi (1935-1939). En este contexto, surgieron algunas colonizaciones fallidas, cuyos objetivos estaban encaminados a poblar las zonas que se encontraban deshabitadas y a salvaguardar la soberanía territorial.

\section{Metodología}

Las colonias de Palena, Quitralco y Melimoyu surgieron por iniciativa del Estado de Chile (ver Imagen 1). Éstas se desarrollaron en diferentes períodos de tiempo, sin embargo, no lograron prosperar y cumplir su objetivo principal de poblar el territorio. Estos elementos son los que nos hacen plantearnos algunas interrogantes: ¿qué metas buscaba alcanzar el Estado, con estos pueblos?, ¿por qué motivos sus habitantes abandonaron sus instalaciones?, ¿qué factores provocaron sus fracasos? A partir de estas dudas surge nuestra investigación. Su objetivo principal es reconstruir la historia de estos poblamientos, para ello, hemos decido utilizar como herramienta de análisis el concepto de colonización, tomando en cuenta su elaboración y realización.

Al estudiar este término podríamos decir que se encuentra ligado al de migración, ya que implica un movimiento de población que se manifiesta a través de la invasión, la conquista y los poblamientos (Fairchild 1963). En términos geopolíticos, puede ser utilizado como una herramienta de resguardo de las fronteras de los países para evitar conflictos limítrofes futuros (Vicens 1961).

En los tiempos modernos, la colonización se entendía como la ocupación territorial, la explotación económica y la dominación política y cultural de un país, algunas veces, estaba respaldada por el Estado, y en otras ocasiones, se refería a un poblamiento de carácter espontáneo (Tobasura 2003). En el siglo XX, la colonización dirigida era de responsabilidad estatal. Las funciones que desarrollaba estaban encaminadas a la selección de las áreas de poblamiento, la elección de los colonos, la construcción de infraestructura, la provisión de los capitales necesarios para su instalación, además de mantener una supervisión o control de sus habitantes (Eulacio 1968).

Todo esto nos indica que existía un compromiso legal entre esta institución y sus pobladores, por consiguiente, se debía estudiar previamente la planificación, ejecución y gestión de estos 
Imagen 1. Colonizaciones fallidas del litoral de Aysén

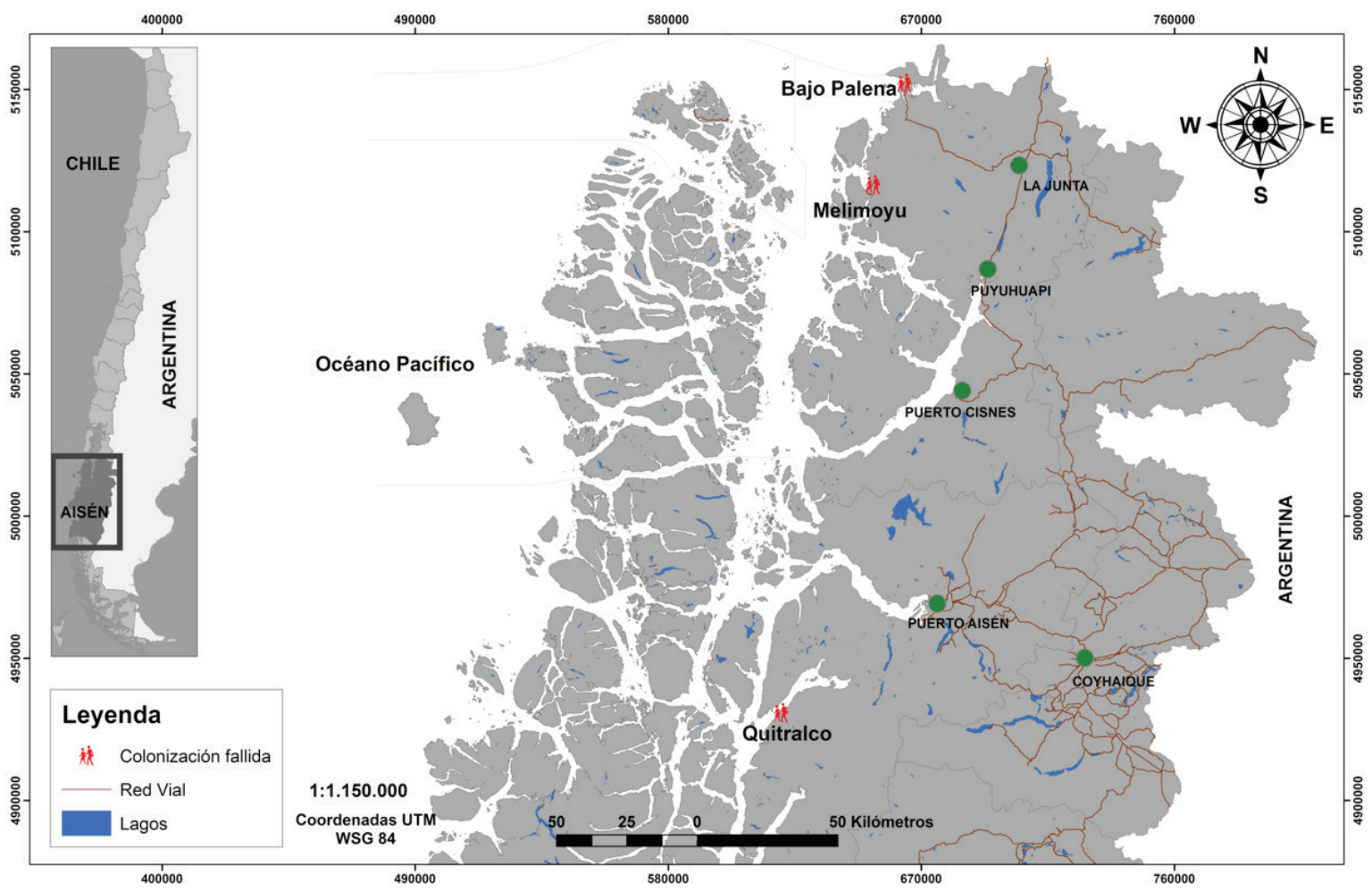

proyectos, incluyendo la fiscalización y el cumplimiento de las obligaciones contraídas. Cuando el Estado no cumplía con estas responsabilidades, caía en una contradicción respecto a sus funciones y los objetivos que buscaba alcanzar. Esto se puede definir como un tipo de violencia estructural (Martínez y García 2004) 3 que afectó directamente a los colonos y sus poblamientos.

3 Desde la perspectiva de Johan Galtung (Cit. en Lederach 1984), este tipo de violencia se refiere a las injusticias que emanan de estructuras desiguales de poder, lo que conlleva la denegación de lo que resulta elemental para la vida de las personas. En nuestros casos, cuando el Estado se desentiende de su función garante, abandona a los habitantes y deja de asumir su labor colonizadora.
Este trabajo está basado en una revisión bibliográfica que rescata los testimonios de colonos y testigos que fueron partícipes de estos poblamientos. Es importante mencionar que existen dos tesis de antropología, cuyas temáticas son las colonizaciones de Quitralco (Aránguiz 1988) y Melimoyu (Cid y Fuster 1989). Estas memorias fueron sumamente importantes para obtener mayor información de la vida de los pobladores, además de incluir los registros del trabajo de campo. Para complementar las fuentes bibliográficas hemos utilizado dos entrevistas, una fue realizada a Genoveva Orrego, en el año 2013 (colona de Quitralco), y la otra corresponde a Carlos Sackel (colono 
de Melimoyu y ex intendente de la Región de Aysén), llevada a cabo en el año 2008.

\section{Las colonizaciones fallidas en el litoral de la Región de Aysén}

\subsection{La fundación de la colonia de Palena o la Isla de Los Leones}

La colonia de Bajo Palena ${ }^{4}$ se ubicó en el sector occidental norte de Aysén ${ }^{5}$ y marcó el inicio formal del proceso de colonización inducido por el Estado, cuyo objetivo general era conocer, explorar y poblar los valles interiores y el litoral de la Patagonia aysenina. Sin embargo, el motivo intrínseco bajo el cual nació la idea de poblar está relacionado con los problemas limítrofes que mantenía Chile con Argentina. Debemos recordar que nuestro país estaba regularizando sus límites fronterizos (Lagos 1980), especialmente la zona que comprendía la cuenca hidrográfica del Palena. Prueba de ello fueron las expediciones llevadas a cabo a finales del siglo XIX, cuyos objetivos eran encontrar el origen de este río y los recursos económicos que se podían explotar en dicha zona ${ }^{6}$ (Barros 1984). Por este motivo, se hacía necesario poblar el sector oriental y, de paso, incentivar el avance de los chilenos a los valles interiores.

Este intento de colonización no tenía otro fin más que el de estar alerta a cualquier iniciativa de

Proyección de las coordenadas de los sitios en estudio: UTM (WSG 18G), 663970-5152124.

Aysén no existía como una unidad territorial, sus archipiélagos del norte eran vistos como una extensión de la gobernación marítima de Chiloé. En 1889 se fundó la colonia de Bajo Palena y se transformó en un departamento de la Provincia de Llanquihue, teniendo como límite el paralelo 47, la parte sur perteneció al territorio de Magallanes.

$6 \quad$ Las exploraciones de Serrano Montaner en 1885, Adolfo Abbe en 1883 y Hans Steffen en 1893. poblamiento en el vecino país. A esto, debemos sumar las tensas relaciones diplomáticas que mantenía Chile con Perú y Bolivia (a propósito de la Guerra del Pacífico). Por lo tanto, si no hubiera existido este conflicto limítrofe con Argentina, probablemente esta colonización hubiera sido más tardía, o bien, no se habría ejecutado. A partir de los fallos arbitrales y los distintos estudios hechos por peritos chilenos y argentinos, se hacía necesario comenzar a poblar las cercanías de los límites y evitar futuras disputas entre ambas naciones: "la expedición de Fontana trajo como resultado que el gobierno argentino estableciese en 1886 la llamada [Colonia 16 de Octubre], y en vista de los informes del explorador Serrano nuestro gobierno decidió en 1889 la fundación [de la Colonia de Palena]" (Greve 1917: 87).

En el año 1885, después de la expedición de Adolfo Abbe, arribó a la Isla de Los Leones el alemán Antonio Emhardt ${ }^{7}$, junto a Charles Burns de Ancud y Juan Yates. Construyeron algunos ranchos, y trasladaron trabajadores de Chiloé para principiar el roce del monte e iniciar las primeras obras de cultivo (Ortega y Bruning 2004). Años más tarde, en 1889 , se fundó la colonia de Bajo Palena, como un departamento perteneciente a la provincia de Llanquihue ${ }^{8}$, bajo el mandato del intendente Jorge Figueroa. Este funcionario público estaba encargado de las concesiones de los sitios y también de dar el visto bueno al traslado de la población. A continuación, se dispuso la creación de 30 de agosto de 1841; emigró con sus padres el 01 de agosto de 1852 a Corral, Chile, en el velero Australia. Probablemente corresponde a Antonio Emhart que en 1888 intentó la primera colonización de Aysén en la Isla Los Leones. Al respecto, véase http://www.genealog. cl/Alemanes/E/Emhardt/ (consultado en febrero de 2014).

$8 \quad$ La Provincia de Llanquihue se encontraba muy alejada de Palena, esto incidió directamente en la poca comunicación que existió entre ambas. 
una población de 32 manzanas, gracias a un decreto firmado por el Ministro del Interior de ese entonces, Ramón Barros Luco. De esta manera, comenzó el establecimiento de los primeros colonos en la zona.

Claramente, podemos establecer un nexo entre esta colonización y el surgimiento de Melinka (1859). Ambos inicios son similares, ya que se buscaba establecer un punto de explotación de los recursos forestales, pero en esta ocasión el Estado se comprometía a crear una colonia, centrando sus esfuerzos en un poblamiento más que en un negocio. A través de un conjunto de acciones, se intentaba demostrar que existía un compromiso serio entre esta institución y las personas que iniciaban su integración a la zona. No obstante, a pesar de todos los esfuerzos desplegados por sus habitantes, se empezó a vivir una situación caótica, que acabó con el total abandono de sus habitantes:

Viven actualmente cuatro familias de colonos chilotes en Palena. En los años anteriores a (sic) la colonia fue muy frecuentada por jóvenes de Chiloé que andaban en busca de trabajo; pero hoy día, todo el entusiasmo ha desaparecido, como lo experimentamos con daño nuestro, (...) la situación de la colonia, lo repetimos, es poco halagadora. Sería de desear que el Supremo Gobierno y los círculos del país que se interesan por el porvenir de estas comarcas de la costa austral, se empeñasen en descubrir las causas de este abatimiento, y contribuyesen a dar más impulso a un establecimiento de tanta importancia (Steffens 1892-1902: 143).

142 A través de este testimonio, podemos deducir que la mayoría de las personas que alguna vez frecuentaron esta colonia se percataron de que no era rentable vivir definitivamente en esos parajes. La negativa de visitar y trabajar en la zona provocó la deserción de los colonos, pues no tenían un flujo migratorio de apoyo. Si intentamos dilucidar las causas, podríamos afirmar que las condiciones en que vivían las personas no eran las más óptimas, la colonia no generaba un foco de atracción hacia sus visitantes (trabajadores), y mucho menos despertaba deseos de establecerse en aquel lugar. Adicionalmente, se puede desprender que el relator insistía en que el Estado debía tener una mayor preocupación por las familias que estaban radicadas en esa área, para evitar la pérdida de todos los esfuerzos y los recursos invertidos en la zona.

Esto demuestra que las delegaciones de las funciones y los compromisos de las instituciones del Estado no respondían a las demandas y promesas hechas a los colonos. En el año 1891 se produjo el estallido de la guerra civil, lo que empeoró aún más la situación. El presidente Balmaceda dejó el poder y se suicidó. Posteriormente, asumió el presidente Jorge Montt, quien no tenía mucho interés en el proyecto colonizador. Los cambios vertiginosos de gobierno atrasaron la ayuda prometida 9 . En el año 1894 Elías Rosselot, inspector de la Colonia de Palena, envió una carta al ministro, detallando los atrasos de las obras realizadas:

Es lógico, señor Ministro, que mientras más se demore el Supremo Gobierno en dispensar atención a la colonia de Palena y mientras más tiempo transcurra sin que se empeñen seriamente los trabajos que deben llevarse a cabo para dejar la

La crisis social y política del país vivida después de la guerra civil de 1891, junto con los cambios sucesivos de gobierno, tenían como escenario las ciudades centro y norte de nuestro país. 
colonia en aptitudes de poder servir a su objeto, mayor será la suma que habrá que invertir y más difícil la reanudación de las obras abandonadas (1894: 70).

El Estado debía asumir una subvención de $\$ 25.000$ pesos anuales, junto con ello, debía facilitar el transporte de los bienes de los colonizadores hasta Palena. Sin embargo, se hizo caso omiso a las peticiones del inspector de la colonia, y progresivamente se fue desligando de su labor garante. En 1895 el Intendente de Llanquihue envió una carta al Ministerio de CoIonización, con el fin de dar cuenta de la situación que atravesaba la colonia: "no hay sino dos personas que no viven de la renta fiscal y por víveres proporcionados por la administración, y estas dos personas son un pescador y un único colono verdadero que vive en la isla. (...) no es capaz de arrastrar al estéril suelo una papa que valga la pena” (Vergara Cit. en Barros 1984: 59).

El lugar que habitaron los colonos no fue el más conveniente para vivir, ya que sus suelos no eran fértiles. Además, aparece un dato interesante en este testimonio: existían sólo dos personas que no percibían un sueldo fiscal, es decir, que las demás personas no podían subsistir por sí mismas. Esto nos hace suponer que los colonos no estaban adaptados a la zona y no eran los más aptos para colonizar las tierras. En este sentido, el atraso de un sueldo o el no pago de éste significaba morirse de hambre o volver nuevamente a sus lugares de origen ${ }^{10}$. Para empeorar más la situación, el Estado dejó de prestar los servicios de transporte a sus residentes.

$10 \quad$ Entonces no existía un proyecto claro de explotación de los recursos naturales y un plan real de desarrollo. Las familias no tenían un sustento económico sólido o estable, por este motivo debían esperar sus sueldos para poder sobrevivir.
El gobierno, para remediar el mal, obligó por contrato, en 1895, a la Compañía Sud Americana de Vapores, en recompensa de la fuerte subvención que pagaba al vapor Pudeto para hacer el servicio por los canales, que éste debiera tocar una vez al mes en Palena, en sus viajes entre Ancud $i$ Melinka, lo que era tanto más fácil cuanto que quedaba fondeado dos días en Melinka, en donde casi nunca había carga ni pasajeros, i por cuanto el viaje a Palena podía haberse hecho en cinco horas, o en seis a diez desde Quellón, siendo esta última ruta preferible. Pero, por motivos que no alcanzamos a comprender, la Compañía suprimió la escala en Palena quedando la colonia a merced de sus pequeñas i pobres chalupas, que en aquellas latitudes se demoraban, a veces, hasta un mes en ir a traer provisiones, jente i correspondencia de Melinka. I así se perdió la colonia (Weber 1903: 184).

El aislamiento y el incumplimiento de los contratos que tenía el Estado con la naviera gatillaron el abandono de la colonia, por lo que sus habitantes decidieron viajar de regreso a Ancud. Durante esta travesía, una de las embarcaciones zozobró, falleciendo el piloto de la nave José del Carmen Levinieri y el marinero Juan Antonio Quelín (Valdés 2006). Finalmente, en el año 1900, Palena estaba totalmente deshabitada.

A pesar de todas las dificultades vividas en esta zona del litoral, después de aproximadamente 40 años comenzó a florecer nuevamente lo que posteriormente se conoció como Palena, pero con el nombre de Puerto Raúl Marín Balmaceda. Augusto Grosse tenía conocimiento de que en Puerto Palena vivía un colono de apellido Bohle, quien había llegado hacía más o menos 
10 años: "se instaló en la Isla de Los Leones, que se encuentra ubicada en el delta del río en referencia. (...) era este colono el único habitante del lugar; pero ahora último llegaron otros colonos de espíritu emprendedor con lo que supongo que Palena está despertando de un sueño que parecía eterno" (Grosse 1955: 105). Con el paso del tiempo se establecieron familias de origen alemán y también nacional (Helmut, Bohle, Valdés, Bravo). Estos nuevos colonos siguieron la senda de sus antecesores, sabiendo de los fracasos que vivieron las personas que anteriormente tuvieron sus mismos planes.

Si reflexionamos en torno a las funciones y obligaciones del Estado, diríamos que éstas se fueron extinguiendo hasta traspasar la responsabilidad de la empresa a los pobladores. Posiblemente haya influido en la mala administración de la colonia la lejanía de la provincia a la que pertenecía, además del caos reinante que se manifestó en la llamada guerra civil de 1891. Como hemos visto, este plan colonizador fue un intento por resguardar la soberanía territorial del Estado ante la fundación de la Colonia 16 de Octubre, y los problemas limítrofes que mantenía Chile con Argentina. A mediados del siglo $X X$ se inició nuevamente un intento de colonización en el sector occidental de la Patagonia. Sus esfuerzos nuevamente se vieron obstaculizados, ya que se cometieron errores similares a los acaecidos en la Isla de Los Leones.

\subsection{La fundación de la colonia de Quitralco}

La colonización de Quitralco ${ }^{11}$ (Kuschel $1997)^{12}$ se inició en el año 1950, en el sector UTM (WSG 18G), 620046-4930795.

12 La palabra Quitralco proviene del mapudungun "quitral": sur-occidental de la Provincia de Aysén ${ }^{13}$, específicamente, al norte de la laguna San Rafael y al sur oeste de Puerto Aysén. Bajo la iniciativa de Orlando Godoy Arredondo ${ }^{14}$ se comenzó a planear la idea de poblar esta zona del litoral, para ello se entrevistó con el presidente de la época Carlos Ibáñez del Campo (Aránguiz 1988).

Dentro de las motivaciones personales de los colonos que impulsaron este poblamiento, encontramos la atracción ejercida por los hermosos parajes, la soledad y la hostilidad de las condiciones geográficas. Desde una perspectiva estratégica, el Estado buscaba radicar cien familias procedentes de la región metropolitana, obteniendo del Supremo Gobierno ${ }^{15}$ la entrega de 30.000 hectáreas de terrenos en el fiordo Quitralco, sector ubicado al sur del fiordo Aysén(Aránguiz 1988). Contándose con la colaboración de Rolf Butendieck, un misionero adventista, se seleccionó un grupo de 512 personas (Martinic 2004). De esta manera surgió el comité colonizador, el cual se entrevistó con el presidente lbáñez y recibió en un primer momento el apoyo del seguro social como comité organizador.

Los rumores de una colonización en el sur se expandieron, a través de una propaganda mediática que buscaba incentivar a las personas a internarse en aquel territorio desconocido. En ella, se ofrecían todas las implementaciones y

fuego; "co": estero, río, corriente, lo que significa estero de fuego 13 El 30 de diciembre de 1927 se creó el territorio de Aysén gracias al DFL 8.582, dos años después se transformó en provincia.

$14 \quad$ Funcionario del Servicio Nacional de Bienestar y Auxilio Social en la década de 1950.

$15 \quad$ La decisión de colonizar fue del Servicio Nacional de Bienestar y Auxilio Social, el cual no era el organismo adecuado para esta labor. Por su parte, la Intendencia de la Provincia de Aysén no estaba de acuerdo con este plan de poblamiento. 
garantías necesarias para atraer a los futuros colonos. El 20 de junio de 1953 partió la primera expedición con veinte jóvenes, provenientes mayoritariamente de Santiago, quienes tenían distintos oficios: un ingeniero eléctrico, una enfermera universitaria, un electricista, una profesora, etc. El funcionario público Carlos Godoy fue el encargado de trasladarlos hacia el sur. Cuando llegaron a su destino, prometió que a la vuelta traería: a los jefes de familia, una goleta, una barcaza, bueyes, vacas y un aserradero para poder trabajar la madera (Araya 1991).

La primera etapa de esta colonización buscaba sanear el área a poblar; sacando arbustos, cortando árboles y creando rudimentarios campamentos. Una vez realizadas estas tareas, debían explorar la zona y buscar su sustento, ya que los alimentos escaseaban (Aránguiz 1988). El primer encuentro que tuvieron con un paisaje duro e implacable significó la adaptación de estos jóvenes al terreno y a aprender a convivir con la soledad y las escasas posesiones que tenían. La ayuda brindada por los pescadores artesanales les fue de gran utilidad, gracias a ellos los nuevos habitantes aprendieron a pescar y construyeron viviendas mejor equipadas.

En el transcurso de los primeros meses los colonos esperaron a sus familiares y la ayuda prometida por el Estado (víveres, materiales de construcción, etc.). Sin embargo, tuvieron que aguardar hasta octubre de 1954 para ver cumplido lo prometido. Después de meses de trabajo y esmero se construyeron las primeras casas definitivas y, con esto, se mantuvo en pie el plan de colonización. Rodolfo Zimmermann recuerda su llegada: "había varios grupos inscritos para venir a Aysén. Mi grupo estaba formado por seis personas que salimos de
Santiago a principios de junio del año 55, llegamos a Puerto Aysén el 20 de julio, allí tuvimos que esperar hasta conseguir una lancha. Lo curioso fue que en Santiago nos dijeron que podíamos ir en micro a Quitralco, porque ni lo conocían" (Hernández y Zimmerman 1986: 14).

El testimonio de este habitante nos demuestra el nulo conocimiento que tenían los colonos y las autoridades santiaguinas del lugar que estaban poblando. En este relato se puede argüir que los participantes de esta empresa tenían una cuota de responsabilidad en este proyecto, ya que no se les ocurrió viajar antes para conocer el terreno, ni mucho menos pensaron en las consecuencias que podría traer el desamparo del Estado. Mientras llegaban más colonos al asentamiento, se hacía más notoria la falta de gente con conocimientos de la vida rural. Esta necesidad incentivó la llegada de los primeros pobladores oriundos de Temuco, los cuales tenían experiencia en el trabajo de campo. Esta partida de colonos tenía la ventaja de traer sus propias herramientas: hachas, cuerdas, elementos de labranza, etc. Gracias a ellos, se iniciaron las primeras plantaciones para poder satisfacer las demandas alimenticias. Los conocimientos que poseían sirvieron para enseñar a los colonos de la zona central todo lo necesario en materia de cultivos y de actividades rurales (Aránguiz 1988). No obstante, surgieron lentamente múltiples complicaciones que deterioraron las relaciones de las personas y su permanencia en Quitralco.

A medida que la gente comenzó a conocer la dura realidad que estaban afrontando, muchos decidieron abandonar la empresa y dirigirse a lugares cercanos, realizando actividades que antes desempeñaban en las ciudades. Como contraparte, existieron personas que 
continuaron con su propósito, a pesar de todos los problemas con los que tuvieron que lidiar. En el año 1956 llegó el tan esperado aserradero, sin embargo, a la hora de desembarcarlo se cayó al mar y se perdió toda esperanza de trabajar la madera.

Los problemas no cesaron y el contacto con el Comité Nacional de Colonización se deterioró (Araya 1998). Una de las causas que perjudicó las comunicaciones entre este comité y el Estado fue la destitución de Carlos Godoy, a causa de unos sumarios de malversación de fondos durante el periodo. A raíz de ello, ya no existiría un intermediario entre el Estado y los colonizadores que se encontraban en la zona.

En ese momento la decisión de quedarse comenzó a tambalear, y una facción de las familias empezó a dudar de la labor de sus dirigentes y de las autoridades (Aránguiz 1988), mientras que la otra tenía la convicción de que la situación podía revertirse positivamente. Las personas intentaron realizar sus últimos esfuerzos para resistir y esperar una ayuda que no llegó ${ }^{16}$. El factor principal que desencadenó el fracaso de esta colonia fue la inexperiencia de vida en lugares extremos, además de tener diferentes ocupaciones antes de llegar a la Provincia de Aysén. Román Hernández recuerda parte de sus sueños antes de arribar a la colonia:

Las primeras motivaciones que tuvimos para venirnos a Aysén fue una gran campaña que se realizó en el tiempo del General lbáñez. Yo trabajaba en la peluquería el "europeo", en Ahumada con Agustinas to, toda la responsabilidad de la empresa recayó en los pobladores.
(...). Nos vinimos porque según las informaciones dadas por el jefe Sr. Orlando Godoy, que era el encargado de la colonización aquí en el sur, no íbamos a tener ningún problema en cuanto a habitación porque habían venido, un tiempo antes, colonos que nos esperaban con terrenos totalmente despejados y con casas hechas (Hernández y Zimmerman 1986: 18).

El entusiasmo al escuchar que las tareas más difíciles estaban hechas era el incentivo para convencer a las personas de que era posible trasladarse y vivir en un nuevo hogar. En el año 1957 la situación ya era insostenible. El aislamiento y la falta de alimentos hicieron que los colonos pidieran ayuda:

Los que acuden al Valle Huemul regresan con la derrota reflejada en el rostro. El poderoso ganadero, no solamente rechaza el negocio, sino que los echa violentamente, notificándolos que si regresaban, dispararían sus armas contra ellos (...). Tras caminar dos días, los muchachos llegaron a Coyhaique y enseguida siguieron a Puerto Aysén. Una vez allí, otros colegas que ya habían escapado del "infierno" colonizador los armaron con ropas presentables y se dirigieron a la intendencia a informar su misión. Al comienzo los funcionarios de esa repartición no creyeron que pudieran haber salido por tierra desde Quitralco, y mucho menos que se hayan atrevido a comerse a los perros (Araya 1991: 80-81).

No existía un clima de expectación en la provincia de Aysén en torno al poblamiento que se estaba llevando a cabo. Pocas personas tenían conocimiento de los problemas que estaban teniendo los colonos en Quitralco. La 
colonización se veía como algo lejano y ajeno a los residentes de las localidades cercanas. El hecho de no conseguir ayuda inmediata y de no superar el aislamiento, afectó el abastecimiento de los colonos y cortó los canales de comunicación con el exterior ${ }^{17}$. En el año 1958 comenzó el éxodo a sus lugares de origen y se terminó uno de los últimos procesos de poblamiento. Al parecer, el Estado no apoyó esta colonización, porque no tenía una voluntad real de poblar. Si bien existió una motivación de parte de los colonos, sus esfuerzos se vieron limitados por los mismos aparatos del Estado.

\subsection{La colonización de Melimoyu}

La colonización de Melimoyu ${ }^{18}$ se inició en los años ochenta durante el régimen militar, escenario en el cual se vivieron fuertes tensiones políticas y sociales en nuestro país. En esta década el Estado tenía como misión incorporar y aprovechar los terrenos fiscales con escasa densidad de población, con el fin de distribuir de mejor manera sus habitantes (Peri 1989). Éste sería el último esfuerzo que realizó el Gobierno de Chile para poner fin a un gran número de fracasos de poblamientos.

En el año 1983 el esfuerzo colonizador se concentró en la península de Melimoyu, ubicada en el sector noroccidental de la Región de Aysén (Comuna de Puerto Cisnes). El poblamiento se denominaba: "Plan Experimental de Poblamiento Área Puyuhuapi o ex reserva Puyuhuapi”, y tuvo por objetivos desafectar

\footnotetext{
$17 \quad$ La falta de un centro neurálgico cercano impidió la comunicación con las autoridades centrales. Adicionalmente, no existió un polo de atracción económico cercano (lo más próximo era Pto. Aysén).

18 Proyección de las coordenadas de los sitios en estudio: UTM (WSG 18G), 652773-5116559.
}

la reserva forestal Puyuhuapi y asentar un número determinado de familias interesadas en desarrollar actividades compatibles con los recursos naturales existentes. Para esto, el Estado subdividió las 171.593 hectáreas de la zona en 58 lotes, asignados por postulación a través de proyectos ${ }^{19}$. En la adjudicación de estas tierras se consideraron algunos criterios de selección como el nivel técnico, económico y cultural de los postulantes, así como la cercanía a los centros de apoyo (Puerto Raúl Marín Balmaceda, Puerto Cisnes, Puerto Puyuhuapi y La Junta), sin embargo, sólo se concretó la radicación definitiva en 33 terrenos. El Estado planeaba reforzar la colonización a través de la construcción de caminos, el otorgamiento de subsidios habitacionales, el tráfico marítimo, y la instalación de algunos servicios públicos.

Si comenzamos a indagar, desde el punto de vista de la distribución de los lotes de tierra y de las actividades económicas que se buscaban llevar a cabo, es importante analizar todo lo que precede a estas acciones, es decir, todo el proceso de planificación previa. En este punto existe una serie de falencias que es importante tomar en cuenta, ya que gran parte de los hechos que ocurrieron en este último intento de poblamiento ocasionaron su fracaso y la deserción de las familias.

El primer error que se presentó fue la falta de información que tenía el Gobierno de la zona que se pretendía colonizar, lo que derivó en una mala planificación e implementación de las políticas de poblamiento. Estas dificultades fueron presagiadas por algunas personas,

\footnotetext{
$19 \quad$ Véase al respecto el Decreto 553 del 1 de septiembre de 1982. Disponible en http://www.leychile.cl/Navegar?idNorma=250137 (consultado en febrero de 2014).
} 
entre ellas Claudio Meneses ${ }^{20}$. El riesgo implícito que se presentaba antes del traslado de los colonos, partía por la definición de las propuestas del proyecto que se buscaba implementar. Dicha información se refería a la carta de uso de suelo, escala de 1:250.000, cuya leyenda identificaba sólo tres elementos de la cubierta vegetal: bosque, matorral y tierra sin uso. Estos elementos de carácter general no fueron suficientes para desarrollar proyectos específicos en el área de colonización(Meneses 1986). La distribución de la tierra, en algunos casos, no concordaba con los proyectos presentados por los colonos. La planificación de estos emprendimientos ${ }^{21}$ se contradecía respecto a las actividades económicas que se iban a desarrollar y el espacio que iban a ocupar. En relación con este tema, Claudio Meneses indicó las siguientes dificultades:

Los tamaños de los predios adjudicados resultan en muchos casos exagerados para el tipo de proyecto que se pretende ejecutar. Especial referencia se hace a los relacionados con los recursos marinos, como por ejemplo el lote $15 \mathrm{a} / \mathrm{e}$, ostrícola y transporte con 5.282 hás. (...) En general los tamaños de estos predios sobrepasan en mucho a las superficies promedios de las propiedades existentes. (...) Los proyectos presentados guardan, en la mayoría de los casos, poca relación con las actividades o experiencias anteriores de los colonos nuevos, lo que podría expli-

20 Decano del Departamento de Geografía de la Universidad de Chile. En la década de 1980, a través de un estudio del Plan de Poblamiento de la Península de Melimoyu, detectó una serie de errores de carácter técnico y de ejecución en la implementación de los proyectos. car (...) la procedencia de los postulantes. La mayoría son de la zona central: Santiago, Valparaíso, Melipilla, Talca y Chillán, y muchos de ellos empleados públicos o de actividades poco relacionadas con los proyectos (1986: 70-75).

Además de los problemas de distribución de la tierra y la incongruencia de algunos de sus proyectos, existe otro tema a discutir, el cual ya ha estado presente en colonizaciones anteriores. Nos referimos a la correcta selección de los colonos y su falta de preparación, antes de trasladarse a un clima y a una geografía inhóspita. La gran mayoría de ellos provenían de la zona central y sus ocupaciones distaban mucho de las actividades económicas que buscaban desarrollar.

Si comparamos este mismo escenario con lo acaecido en Quitralco, diríamos que no existió la creación de un perfil del colono, ni mucho menos fueron puestos a prueba antes de trasladarlos. Por consiguiente, su desempeño no fue óptimo, ya que el cambio de residencia significó un esfuerzo doble para poder desenvolverse de manera plena. A esto debemos agregar las diferentes procedencias de sus pobladores, desde el punto de vista de sus lugares de orígenes, sus culturas y las clases sociales a las que pertenecían. Todos estos factores intervinieron en la cohesión de sus habitantes y en las decisiones que tomaron en conjunto:

debido a las muchas diferencias existentes entre ellos, ya sea respecto de sus estratos socio-económicos de procedencia, de sus valores, de sus ideas religiosas, de su nivel educacional, etc., se producen también múltiples problemas y roces de variadas dimensiones; al no poder venti- 
lar abiertamente estos disgustos (...), nos encontramos con una agresividad no declarada (Cid y Fuster 1989: 72).

Al referirnos a los proyectos económicos, la mayoría de los colonos no tenía experiencia en alguna actividad relacionada con el mar o alguna actividad campestre. Por ende, el trabajo inicial fue lento y no logró prosperar. Don Carlos Sackel recuerda las complicaciones que tuvo que vivir:

así que en el año ochenta y tres, nos plantearon que el programa había sido aprobado y que teníamos asignado un lote de terreno, que evidentemente teníamos que pagar, porque nos vendieron la tierra (...) y en el año ochenta y tres nos fuimos a vivir al sector de Melimoyu en el lote 16 (...) nuestro punto de salida era el incipiente poblado de Melimoyu, donde lo único que había era una oficina de la $\operatorname{ECA}^{22}(.$.$) y no$ había nada más (...). Seguimos trabajando en la pesca, pero como todas estas cosas tienen su ciclo, evidentemente el alga sufrió una variación de precio muy fuerte, por otro lado mi familia tuvo que salir de donde estábamos del poblado, porque la niña tenía que seguir estudiando, yo fui profesor de ella durante (...) tercero, cuarto (...) octavo y como tenía que pasar a primero medio ahí decidimos que tenía que irse del poblado y se fueron a Osorno 23 .

\footnotetext{
22 Empresa de Comercio Agrícola (ECA) era el centro de abastecimiento alimenticio y de elementos domésticos donde los colonos asistían a comprar.

23 Entrevista a Carlos Sackel, Coyhaique, 8 de febrero de
} 2008.
La estadía de este poblador nos demuestra el duro cambio que debió afrontar al trasladarse a un lugar agreste, en el que sólo existía un organismo del Estado. En su experiencia de vida se puede apreciar que no estaba preparado para enfrentar la crisis económica que afectó su proyecto, lo que le hizo replantearse la idea de mantenerse en la zona. La falta de educación para su hija también incidió en la decisión de abandonar su nuevo hogar.

Amedidade queestas dificultades entorpecieron el establecimiento de las personas, la mayoría de ellas fue alejándose de la zona. Entre los años 1983 y 1987 se habían asignado un total de 106 parcelas y lotes, de los cuales sólo se habían entregado 23. En el año 1992, sólo se contaba con un total de 17 familias radicadas de manera definitiva (Padilla 1998). El Estado, al ver que los proyectos productivos no eran viables, decidió cambiar las propuestas de la colonización, designando a nuevas familias y a sociedades particulares la tenencia de la tierra. En el año 1993 la situación desmejoró más, ya que existían colonos que llevaban más de ocho o diez años residiendo en la zona, y aún no tenían regularizada la tenencia de sus tierras. Algunos llevaban más de cinco años tramitando con Bienes Nacionales la entrega de las escrituras. El hecho de no tener el título definitivo impedía categóricamente los préstamos y los créditos, motivo por el cual las iniciativas de carácter económico se vieron frenadas.

Los factores que jugaron en contra de los colonos pueden resumirse en: la falta de proyectos económicos adecuados, el desconocimiento de la zona, la tardía ayuda del Estado y las irregularidades en la entrega de los títulos de dominio. La población comenzó a disminuir por la falta de trabajo y oportunidades, y además se 
generó una contradicción entre el poblamiento real y las inversiones realizadas por el Estado en materia de servicios básicos y proyectos de mejoramiento del pueblo. Los compromisos de inversión se realizaron tardíamente, cuando las personas ya estaban abandonando la zona. Como consecuencia, el remanente de pobladores se vio afectado por la desocupación laboral, y por una reorientación productiva distinta a la que se habían comprometido. Por este motivo, en la década de los noventa, la mayoría de las ocupaciones de los pobladores se relacionaba con los servicios básicos (Padilla 1998).

En este último intento de colonización las condiciones de ocupación mejoraron, a diferencia de otras experiencias. Los recursos estaban disponibles y el Estado estuvo presente, no obstante, su actuar fue tardío y hubo errores que se cometieron en cuanto a la planificación y la selección de los colonos. Estaban dados todos los elementos necesarios para realizar una buena propuesta de poblamiento, pero no se aprovecharon los canales de comunicación que existían, y mucho menos se reflexionó sobre los intentos que fracasaron anteriormente.

\section{Las colonizaciones y sus problemas}

Al estudiar las colonizaciones inducidas por el Estado, encontramos que su base principal es su carácter legal o jurídico. Este tópico merece ser discutido, ya que las leyes y los decretos de colonización implican todo el proceso de planificación e incluyen el conjunto de acciones que se va a llevar a cabo. Por lo tanto, no pueden existir vacíos legales u errores (IICAVINCORA 1974) en su elaboración y aplicación. En Bajo Palena, sus decretos no se respetaron:
No conozco las razones que hayan podido traer el estado deplorable de la colonia de Palena y la contravención de todas las instrucciones primitivas que reglamentaban su fundación. Se me ha asegurado que varias veces han intentado colonos de conseguir su radicación en los valles interiores, como lo disponía la carta fundamental de la colonia; pero la administración no accedió a tales solicitudes (Vergara Cit. en Barros 1984: 59).

En el caso de Quitralco la situación fue más perjudicial, ya que no se contó con el respaldo de un decreto de colonización, todo dependía de una sola persona:

No pudo adaptar su proyecto a la selva institucional (...). De esta manera, la frágil e inestable posición estructural del sistema agente colonizador, su soledad institucional (...), la ausencia de un financiamiento especial y de un reconocimiento jurídico legal, y en fin, sus propios conflictos internos, dieron a este proyecto de colonización (...) condiciones de viabilidad muy negativas (Aránguiz 1988: 283).

El proyecto de colonización en el sector de Melimoyu perjudicó la reserva forestal Puyuhuapi, ya que fue desafectada (Decreto NN 553 del 1 de septiembre de 1982). Esto originó serios daños al ecosistema del litoral norte de Aysén. El 4 de agosto del año 1983 se promulgó el Decreto Supremo № 459, bajo el cual nació el plan experimental de Melimoyu, el cual dependía directamente del Ministerio de Bienes Nacionales (Peri 1989). En el año 1986 la situación cambió y la responsabilidad de esta institución se traspasó a la Intendencia de la Región de Aysén, esto afectó la gestión y los 
trabajos que se habían hecho anteriormente: “a) Ministerio de Bienes Nacionales quien continuará planificando y ejecutando las acciones de colonización que le asignen las leyes vigentes con excepción del programa Melimoyu - Puyuhuapi que será coordinado y desarrollado por el Intendente de la XI Región" (Decreto No 1160 del 21 de octubre 10 de1986).

Uno de los errores más recurrentes que se suele cometer en los poblamientos es la mala planificación de sus emplazamientos, tamaños y dispersión geográfica (Poblete 1961). La escasa información que se tenía del litoral de Aysén y la carencia de estudios serios fueron determinantes en el fracaso de las colonias. Como consecuencia de ello hubo una inadecuada ubicación de estos asentamientos, lejanos a los centros de apoyo y con una baja calidad de sus suelos: "la colonia no prosperó, fundamentalmente por las distancias que separaban a la población (desembocadura del río) y los lugares de pastoreo (plena zona interior)" (Izquierdo 1990: 102). Similar situación se presentó en el sector de Quitralco: "un pueblo aislado por mar y tierra, lejos de cualquier centro poblado y fuera de la ruta marítima. (...) Aunque en esto incidieron los intereses territoriales no resueltos, en otras áreas más propicias de la región. Y en esta mala localización, la creación de un PUEBLO" (Aránguiz 1988: 285).

El aislamiento geográfico y la falta de centros neurálgicos de apoyo no fueron los únicos factores que provocaron el fracaso de estos poblamientos. También existen vestigios que demuestran serias falencias en los diagnósticos y estudios que se hicieron en estos lugares:

así las limitaciones parecen ser mayores que las potencialidades y la accesibili- dad se encuentra limitada a la costa y a los valles que penetran al interior, todo concuerda con las recomendaciones de COSERREN (1981) en el sentido de que el área es mayormente indicada para ser el Parque Nacional y una de las tres de la región que debiera ser reserva forestal (Romero 1986: 80).

La colonización depende de la migración de sus habitantes, de allí que su arribo es fuente de nuevos patrones culturales, es decir, diferentes relaciones con los ecosistemas y el ambiente, otras formas de producción, la formación de diferentes estructuras sociales y un proceso de adaptación (Fajardo y Mondragón 1997). Para poblar es necesario realizar una selección de las personas más idóneas para formar parte de estos asentamientos. Dentro de este punto, es importante decir que el perfil del colono debe ajustarse a los parámetros que exige el Estado al momento de trasladarlos a sus nuevos hogares (Cisterna 1978).

Esto se puede complementar con un sistema de producción que les permita satisfacer sus necesidades básicas (García 1999), de esta manera, su estadía se puede prolongar en el tiempo. En Melimoyu no se contextualizaron de manera efectiva las actividades económicas a desarrollar: "hubo un colono que no pudo implementar su proyecto económico, por tratarse de una actividad en el área de servicios (gasfitería), que por la cantidad de población y la realidad del sistema de alimentación de agua potable (...) aún no es requerido por la comunidad (...) no le quedó otro camino que renunciar" (Cid y Fuster 1989: 50).

En las colonizaciones anteriores la mayoría de las personas provenía de la zona central y la 
zona sur, si bien algunos eran profesionales, esto no les bastó para poder enfrentar el aislamiento geográfico y el clima adverso. La falta de capacitación técnica y asesoramiento de los colonos (IICA/CIRA 1964) fue una limitante en las tareas que buscaban cumplir: "menos mal que la gente de la Araucanía sabía sembrar, los de Santiago nada. Se hacía madera pero para construcción de las casas, cercos, no se vendía. Nunca se armó industria de nada"24.

También existieron serios retrasos en la ejecución de las tareas que estaban programadas. Dentro de este ámbito, no existió un compromiso formal de parte de las instituciones públicas encargadas de la colonización (es decir, presencia directa):

pero sí puedo afirmar que en el terreno de la isla no hay rastro de trabajos que dejen suponer siquiera la existencia de la idea de un plano. Lo que existe en la isla es una casa de administración construida con materiales llevados de Puerto Montt, espaciosa, bien hecha, pero inconclusa, con un valor de cuatro mil quinientos pesos; una docena de ranchos diseminados en la duna sin más ley que el capricho para su ubicación, una lancha a vapor completamente inutilizada por el descuido y la intemperie, y finalmente (...) cuatro hectáreas limpiadas en toda la superficie de mil doscientas que cuenta la isla (Vergara Cit. en Barros 1984: 59).

Todos estos inconvenientes sucedieron porque los aparatos públicos del Estado no trabajaban coordinadamente para resolver los problemas que se presentaban: "el sistema que hacía de del 2013.

Entrevista a Genoveva Orrego, Santiago, 16 de noviembre agente colonizador, Bienestar y Auxilio Social, entraba en abierta competencia de funciones con otros más [Ministerio de Tierras y Colonización] y violaba la jurisdicción de otros más [Intendencia de Aysén]" (Aránguiz 1988: 268).

El Estado no contempló una igualdad de oportunidades o una mayor responsabilidad con los colonos, como cualquier ciudadano de nuestro territorio nacional. En materia asistencial o de apoyo a las garantías básicas (Arnello 1985), su accionar fue negligente, esto se tradujo en un tipo de violencia estructural (La Parra y María Tortosa 2003): "ocurrió entonces la muerte de una guagua. Rápidamente se armó una comisión de colonos que fue a Santiago a reclamar y a exigir que se les dijese si cumplirían con la entrega de víveres" (Aránguiz 1988: 202).

La tardía incorporación de los servicios básicos tuvo graves consecuencias: "desgraciadamente los servicios básicos que ahora vemos, edificios hermosos, llegaron 6 años después que los colonos estaban ya en Melimoyu (...) el no haber contado en su tiempo con la escuela básica, con la posta y otro tipo de servicio, hizo que el 50 por ciento de la población emigrara" 25 . Adicionalmente, la falta de recursos económicos incentivó un nuevo proceso de migración a los lugares de origen: "durante nuestros terrenos se produjeron tres casos de deserción en el área estudiada, pero esta vez, el motivo principal fue, claramente, el factor económico" (Cid y Fuster 1989: 5).

Una de las etapas más importantes dentro de las colonizaciones es la regularización de la tenencia de la tierra ${ }^{26}$. En esta fase es de suma

\footnotetext{
$\begin{array}{ll}{ }_{25} & \text { El Diario de Aysén, 25/05/1996, página } 6 . \\ { }_{26} & \text { Véase http://www.fao.org/docrep/005/y4307s/y4307s05. }\end{array}$

${ }_{25}$ El Diario de Aysén, 25/05/1996, página 6.
${ }_{26}$
Véase http://www.fao.org/docrep/005/y4307s/y4307s05.

tm
} 
importancia reconocer la antigüedad del colono y la autenticidad de los títulos de propiedad, sobre todo, cuando se producen cambios en las cláusulas de las leyes y los decretos de colonización. En los años cincuenta aún no existía un organismo con presencia física que atendiera los problemas o reclamos de tenencia de la tierra. Todos los expedientes, para efectos de los otorgamientos de los permisos de ocupación, títulos provisorios y títulos de dominio definitivos, debían ir en trámite al Departamento de Bienes Nacionales y Colonización (Ministerio de Propiedad Austral) ${ }^{27}$, y en repetidas ocasiones la falta de uno solo de ellos era motivo de regreso, sólo para que el interesado cumpla con la ley de timbres y estampillas.

Si reflexionamos profundamente en esta materia, podríamos decir que el fácil acceso y el corto tiempo de prórroga para adquirir un terreno, pueden hacer fracasar la misión de poblar un lugar. El colono se puede establecer por un período de tiempo acotado, realizar algunas mejoras en su terreno y posteriormente venderlo a un precio mayor, sin un esfuerzo y una voluntad real de habitar. Por el contrario, la gran cantidad de años que un colono vive en una zona y el excesivo tiempo de retraso en la adquisición del título de dominio (Feliú 2000)28 disminuyen las esperanzas de establecerse definitivamente: "no más de 5 familias lograron su título definitivo de propiedad, puesto que primero debían declarar los campos y pedir los permisos de ocupación a la Oficina de Tierras (...) en estas circunstancias, como se ve, la gran mayoría quedó a la mitad de camino de los requisitos" (Aránguiz 1988: 145).

\footnotetext{
$27 \quad$ Véase http://www.bienesnacionales.cl/?page_id=1567 Los títulos de dominio son los antecedentes que acreditan el dominio de un inmueble. Se accede a ellos cuando el propietario va a ejercer su derecho a disponer de él.
}

El sistema de arrendamientos y las demoras en la concesión de los títulos de tierra frenan la ejecución de valiosas obras, las que constituyen mejoras perdurables para el predio, ya que el colono no sabe si va a poder recuperar su inversión. Todas estas barreras impidieron la obtención de préstamos bancarios para mejorar las tierras (Hurtado y Brown 1959), porque no se podían ofrecer los terrenos en garantía: "organizaciones campesinas, parlamentarios y diversas autoridades han reiterado la necesidad de agilizar el trabajo de mensura y entrega de los títulos correspondientes a los pobladores, que en el caso de los más antiguos, por décadas no tienen acceso al crédito en diversas entidades $y$, por ende, no pueden progresar" 29 .

Todos estos aspectos jugaron en contra de los pobladores y entorpecieron los planes de ocupación. En el último intento de colonización no se tomaron en cuenta las experiencias anteriores y otros intentos de poblamientos que pretendemos estudiar posteriormente: la colonia gallega en la desembocadura del Río Aysén (1900) y el plan de colonización de la Isla Magdalena dirigido por la Pontificia Universidad Católica de Chile (1979). Actualmente, Puerto Raúl Marín Balmaceda es el único pueblo que logró sobrevivir al intento colonizador de la Isla de Los Leones. Melimoyu se encuentra casi abandonado, ya que la mayoría de las familias vendieron sus terrenos, a lo que debemos sumar la intervención de la fundación Melimoyu (conservación de ecosistemas de Chile). En el caso de Quitralco, este sector quedó totalmente abandonado. 


\section{Conclusiones}

En la reconstrucción histórica y en el análisis de las colonizaciones mencionadas y sus problemas se identificaron algunos factores o elementos de continuidad, los cuales incitaron el abandono de estos poblados. Si bien se desarrollaron en diferentes períodos de tiempo, dichas colonizaciones poseen ciertas similitudes en las causas de sus abatimientos. Existen dos elementos transversales que se destacaron en sus fracasos, nos referimos a la planificación y la gestión de estas empresas.

En las colonias se encontraron serias deficiencias y errores en la creación de estos proyectos, lo que afectó derechamente sus bases legales: leyes, decretos de colonización, diagnósticos y estudios previos de las zonas que pretendían habitar. Adicionalmente, la ubicación estratégica de estos centros poblados se encontraba muy alejada de los puntos de apoyo o socorro. En relación a sus pobladores, los requisitos utilizados en su selección no fueron rigurosos. En concomitancia con los errores cometidos en materia de planificación, posteriormente se presentaron graves problemas de gestión en las instituciones encargadas de esta tarea: burocracia fiscal, falta de compromiso del Estado en materia de asistencialidad, postergación de los colonos (incumplimiento de las garantías básicas para mantenerse en la zona), y una tardía entrega de los títulos de dominio.

Los poblamientos dirigidos en el litoral obedecen a un patrón de colonización diferente al de la zona continental. El poblamiento interior estaba ligado a las concesiones de tierras a personas o empresas jurídicas; mediante convenios con el Estado se hacían dueñas de áreas vírgenes para fines productivos. Los objetivos de estas empresas estaban destinados a la realización de negocios, más que a emprender un poblamiento. La misma situación se presentó en el litoral, Aysén representaba un gran stock de recursos marinos y forestales a explotar, por esta razón se iniciaron los movimientos migratorios al sur, bajo la iniciativa empresarial no existió una voluntad real de habitar la Patagonia. Las colonizaciones estatales costeras tenían como necesidad asentar colonos, ése era su objetivo principal, sin embargo, derivaron la mayoría de sus obligaciones y responsabilidades a sus habitantes, por lo tanto, era poco probable que estos emprendimientos funcionaran.

Si comparamos estas experiencias vividas en Aysén con los procesos de colonización sucedidos en el territorio sur de nuestro país, podríamos decir que fueron diferentes. Para tener una mejor comprensión en esta materia es importante analizar el caso de la colonización de Llanquihue ${ }^{30}$. Si bien se desarrolló en un tiempo y espacio diferente al de las colonizaciones fallidas de Aysén, existió un mayor grado de preocupación y responsabilidad por parte del Estado en cumplir las obligaciones contraídas con sus colonos, y con el objetivo de poblar la zona que buscaban potenciar económicamente.

\footnotetext{
$30 \quad$ Véase Pérez Rosales (1859).
} 
Agradecimientos a:

Francisco Mena (doctor en arqueología CIEP), Ana Ansón (geógrafa),

Carlos Castillo Levicoy (ingeniero forestal), Anahí Huechan (tecnóloga médica SOHIGEO), Genoveva Orrego (colona de Quitralco), Carlos Sackel (colono de Melimoyu),
Mauricio Osorio Pefaur (antropólogo Ñire Negro). A los profesores Hernán Delgado (PEDCH), Mónica

Foitzick,

Luis Paredes y Sor Verena Bustamante (Mater Dei). A toda mi familia, por estar siempre junto a mí.

En memoria de: María Teresa Lleucún Burgos.

\section{Bibliografía}

Aránguiz, E. 1988. Viabilidad y adaptación de los sistemas sociales: Un estudio antropológico histórico sobre el experimento colonizador de Quitralco. Tesis para optar al grado de Antropólogo Social. Santiago: Universidad de Chile.

Araya, B. 1998. El gran reportaje de Aysén. Aysén: Programa aplicación y recopilación bibliográfica cultural.

1991. Aysén siglo XXI. Santiago: Carabineros de

Chile.

Arnello, M. 1985. "Políticas a largo plazo para el desarrollo austral". Revista Trapananda 5: 14-18.

Barros, J. M. 1984. Palena: Un río, un arbitraje. Santiago: Santillana del Pacífico.

Brinck, G. et al. 2011. Las mutaciones de la merluza austral. Historia, cultura y economía política en Isla Toto / Puerto Gala. Santiago: Editorial Cuarto Propio.

Carrasco, G. 2002. Hans Steffen - Pedagogo, geógrafo, explorador, experto en límites. Santiago: Edición Instituto Geográfico Militar.

Cid, S. y Fuster, A. 1989. Abriendo nuevos horizontes. Colonos en la selva patagónica. Tesis para optar al grado de Antropólogo Social. Santiago: Universidad de Chile.

Cisterna, F. 1978. Proposiciones para una política de desarrollo regional de Aisén. Revista Trapananda 1: 61-70.

Eulacio, A. 1968. Los conceptos y problemas de colonización en América Latina. Brasilia: FAO.

Fairchild, H. 1963. Diccionario de Sociología. México D.F-Buenos Aires: FCE.

Fajardo, D. y Mondragón, H. 1997. Colonización y estrategias de desarrollo. Santafé de Bogotá: IICA.

Feliú, J. 2000. Manual de estudio de títulos. Santiago: Editorial Jurídica de Chile.

García, E. 1999. Colonización y medio ambiente. Tibaitatá: CORPOICA-Plan Nacional de Desarrollo Alternativo.

Greve, E. 1917. "Informe sobre la delimitación provincial y departamental en Llanquihue y Chiloé". Revista Chilena de Historia y Geografía 25 (XXI): 81-110.

Grosse, J. A. 1955. Visión de Aisén. Exploraciones del explorador Juan Augusto Grosse. Santiago: IGM.

Hernández, R. y Zimmermann, R. 1986. "Quitralco: Vivencias de una colonización". Aysén Tierra Adentro 5: 14-24.

Hurtado, C. y Brown, R. 1959. Seminario de investiga- ción sobre el desarrollo de la provincia de Aisén. Santiago: Ediciones del Departamento de Extensión Cultural de la Universidad de Chile.

Ibáñez, A. 1972-1973. "La incorporación de Aisén a la vida nacional, 1902-1936". Revista Instituto de Historia de la Universidad Católica de Chile 11: 259-278.

IICA/CIRA. 1964. Seminario sobre programación y administración de reforma agraria. Noviembre 9-18-1964. Maracay, Venezuela. Turrialba: IICA.

IICA/INCORA. 1974. Seminario nacional sobre criterios para programas de colonización. Bogotá: IICA.

Ivanoff, D. 2002. La guerra de Chile Chico o los sucesos del Lago Buenos Aires. Coyhaique: Editorial Cruz del Sur de la Trapananda. go: Andrés Bello.

Izquierdo, G. 1990. Historia de Chile. Tomo III. Santia-

Kuschel, C. 1997. Apellidos Huilliches Mapuches Pehuenches. Santiago: Impresión Centro Gráfico Prisma.

Lagos, G. 1980. Historia de las fronteras de Chile: Los tratados de límites con Argentina. Santiago: Andrés Bello.

La Parra, D. y María Tortosa, J. 2003. "Violencia estructural: Una ilustración del concepto". Revista de Estudios Sociales y de Sociología Aplicada 131: 57-72.

Martínez, A. y García, C. 2005. Jugando en paz: Propuestas para jugar en paz y sin violencia. Madrid: Narcea.

Martinic, M. 2004. De la Trapananda al Aysén. Santiago: Pehuén Editor.

1977. "Ocupación y colonización de la región septentrional del antiguo territorio de Magallanes, entre los paralelos $47^{\circ}$ y $49^{\circ}$ sur". Anales del Instituto de la Patagonia 8: 1-57.

Meneses, C. 1986. "Análisis del proceso de colonización sobre la base del uso y manejo de los recursos ambientales en el área de la Ex-Reserva Puyuhuapi, XI Región”. Revista Geográfica de Chile Terra Australis 29: 61-93.

Morales, D. 2014. "El negocio de la madera: Comerciantes y "hacheros" de Chiloé, 1850-1875". Revista Magallania 42 (2): 41-60.

Ortega, H. y Bruning, A. 2004. AISÉN. Panorama histórico y cultural de la XI Región. Santiago: LOM.

Osorio, M. 2014. Antiguas historias del Valle Simpson Región de Aysén. Coyhaique: Ediciones Ñire Negro. 
Padilla, C. 1998. "Melimoyu: Un caso de colonización dirigida en la historia reciente de Aisén". Cuadernos de Historia y Cultura de Aysén 3-4: 35-37.

Pérez Rosales, V. 1859. Ensayo sobre Chile. Santiago: Librería del Ferrocarril.

Peri, R. 1989. Reseña de la colonización en Chile. Santiago: Andrés Bello.

Poblete, M. 1961. La reforma agraria en América Latina. Santiago: Andrés Bello.

Pomar, J. 1923. La concesión del Aisén y el Valle Simpson. Santiago: Imprenta Cervantes.

Romero, H. 1986. "Planificación, realidades y contradicciones de la colonización de Aisén". Revista Ambiente y Desarrollo 2: 75-89.

Rosselot, E. 1894. "Inspección de la Colonia de Palena. Memoria del Inspector de la Colonia de Palena". Revista Trapananda 3: 55-70.

Saavedra, G. 2011. Perspectivas culturales del desarrollo en las costas australes de Chile. Aproximación antropológica a las persistencias y transformaciones de las economías de pesca artesanal en el litoral de Aisén. Memoria para optar al grado de Doctor en Antropología. Madrid: Universidad Complutense de Madrid.

2005. "Las economías silenciosas del litoral aisenino". Otras narrativas en Patagonia. Tres miradas antropológicas a la Región de Aisén. Osorio, M. (Ed.). Santiago: Ediciones
Nire Negro. 35-63.

Simpson, E. 2011. Viajes de exploración por los archipiélagos australes. Temuco: Ofqui Editores.

Steffen, H. 1892-1902. Viajes de exploración y estudio en la Patagonia occidental. Vol. I. Santiago: Cámara Chilena de la Construcción-Pontificia Universidad Católica de Chile-Dirección de Biblioteca Archivos y Museos.

Tobasura, I. 2003. Boyacenses en Caldas: Una colonización silenciosa. Manizales: Editorial Universidad de Caldas.

Torrejón, F. et al. 2013. "Descifrando la historia ambiental de los archipiélagos de Aysén, Chile: El influjo colonial y la explotación económica-mercantil republicana (siglos XVI-XIX)". Revista Magallania 41 (1): 29-52.

Valdés, L. 2006. Poblamiento del litoral norte e insular de Aysén. Tesis para optar al título de Profesor de Historia y Geografía. Puerto Cisnes: Universidad de Los Lagos.

Vicens, J. 1961. Tratado general de geopolítica. Barcelona: VICENS-VIVES.

Vidal, F. 1905. Estudios geográficos e históricos de D.

Francisco Vidal Gormaz. Santiago: Imprenta Cervantes.

Weber, A. 1903. Chiloé. Su estado actual. Su colonización. Su porvenir. Santiago: Imprenta Mejía.

Westhoff, F. 1867. "Jeografía y meteorología chilena. Memoria del subdelegado marítimo del archipiélago de los Chonos o Guaitecas". Anales de la Universidad de Chile 7 (XXIX): 445474. 